\title{
Fanconi anemia manifesting as a squamous cell carcinoma of the mandible: a case report
}

\author{
A. Pinar Erdem ${ }^{1}$, G. Ikikarakayali ${ }^{1}$, N. Yalman $^{2}$, G. Ak ${ }^{3}$, M. A. Erdem ${ }^{4}$, M. B. Bilgic ${ }^{5}$, E. Sepet ${ }^{1}$ \\ ${ }^{1}$ Department of Pedodontics, Dentistry Faculty, Istanbul University, Istanbul, Turkey; \\ ${ }^{2}$ Department of Medical Biology, Istanbul University, Istanbul, Turkey; \\ ${ }^{3}$ Department of Oral Surgery and Medicine, Dentistry Faculty, Istanbul University, Istanbul, Turkey; \\ ${ }^{4}$ Department of Oral and Maxillofacial Surgery, Dentistry Faculty, Istanbul University, Istanbul, Turkey; \\ ${ }^{5}$ Department of Pathology, Istanbul University, Istanbul, Turkey. \\ E-mail: goksenkayali@gmail.com
}

Received 16 March 2011; revised 20 April 2011, accepted 3 May 2011.

\begin{abstract}
Progressive bone marrow failure and development of malignancies, particularly acute myeloid leukemia and solid tumors the most important features of Fanconi's Anemia (FA). This paper reports the case of a 16-year-old patient with FA who developped squamous cell carcinoma of the mandible, ten years after the bone marrow transplantation (BMT).
\end{abstract}

Keywords: Squamous Cell Carcinoma; Fanconi's Anemia; Mandible; Bone Marrow Transplantation

\section{INTRODUCTION}

Fanconi's anemia is an autosomal recessive disorder characterized by constitutional aplastic anemia and congenital abnormalities [1]. FA is defined by chromosomal breakage in which many patients present with pancytopenia, hypoplastic bone marrow, hyperpigmentation of the skin, skeletal malformations, small stature, hypogonadism, and chromosomal aberrations [2]. FA is characterized by a high degree of genomic instability and predisposition to cancer development [3]. The most important features of FA are progressive bone marrow failure and development of malignancies, particularly acute myeloid leukemia and solid tumors [4,5]. Such patients are prone to the development of hematological malignancies and squamous cell carcinoma, especially of the head and neck [2,6,7].

FA is characteristically defined by its cellular hypersensitivity to DNA cross-linking agents such as diepoxybutane and mitomycin [2,8]. Based on the presence of mutations in one of the FA genes, FA can be divided into 8 complementation groups (A-G, including D1 and D2), with each group having in common the cellular hypersensitivity to cross-linking agents $[9,10]$. Current therapy regimen consists of supportive treatment and androgens, steroids and cytokines. But allogenic bone marrow transplantation is the definite treatment of choice for FA patients with progressive bone marrow failure. FA patients are at risk for secondary malignancies, for example leukemia, squamous cell carcinoma and hepatocellular carcinoma $[11,12]$. The risk of squamous cell carcinoma development is especially high in the anogenital region as well as the head and neck region [1].

A review of the literature revealed 40 cases of SCC in FA patients. 14 of these cases involved oral carcinoma, with tongue being the most frequently affected site. In this review, all of the reported SCC in FA patients originated in mucosal and mucocutaneous sites, especially oral $(n=25)$ and anogenital sites $(n=8)$ and the esophagus $(n=6)$, with the exception of two patients with multiple cutaneous involvement [1].

We report SCC of the mandible in a patient with FA. Only one case of SCC of the mandible in a patient with FA patient was reported in 1980 by Vaitiekaitis AS et al. This is a report of a second case.

\section{CASE REPORT}

We report the case of a 16-year-old boy with squamous cell carcinoma (SCC) of the mandible. On January 2, 2008 he was referred to Istanbul University, Faculty of Dentistry with a mass on the right side of the mandible. FA with an unknown complementation group had been diagnosed at the age of 5 years. He is the second child of the consangenious marriage. He underwent BMT at 1998 with marrow donated by her HLA-identical sister who did not have FA. Pre-transplant conditioning consisted of cyclophosphamide $20 \mathrm{mg} / \mathrm{kg}$ + total body irradiation (TBI) 750 cGy (n:11). At 1998 before the BMT the dosage of the medicine regimen was changed as 
cyclophosphamide $20 \mathrm{mg} / \mathrm{kg}+$ TBI $500 \mathrm{cGy}+$ antithymocyte globulin (ATG) $10 \mathrm{mg} / \mathrm{kg}$ (n:2) He suffered from graft-versus-host disease (GvHD) (grade II-III) and had complete hematologic reconstitution during transplantation. For GvHD prophlaxis, they used CSA, because of GvHD, PRD was given to the patient. This was treated with cyclosporin A. Four weeks after BMT, CMV infection had occured. In accordance to this, pnömonia and cerebral disorder were observed. For treatment of these disorders, gansikolvir + CMV Ig G was given to the patient. Between 1999-2003 Cy $40 \mathrm{mg} / \mathrm{kg}+\mathrm{Bu} 6 \mathrm{mg} / \mathrm{kg}+$ ATG $20 \mathrm{mg} / \mathrm{kg}$ was applied. He did not come to his medical controls between 2004 - 2008. When he came in 2008, blood observations were repeted. Full blood count was found normal. According to the microbiological observations in 2008, anti-CMV Ig G was found positive.

Oral examination disclosed caries of molar teeth, periodontitis and restricted oral opening. There was a fungating purulent lesion of the right side of the mandible (Figure 1(a) and (b)). He had severe mucositis interrupting his oral feeding. The panaromic radiograph of the patient was shown in Figure 2.

The lesion was examined with CT and MR imaging and diagnosed as SCC after an incisional biopsy. Microscopic findings of biopsy include two elastic tissue parti-

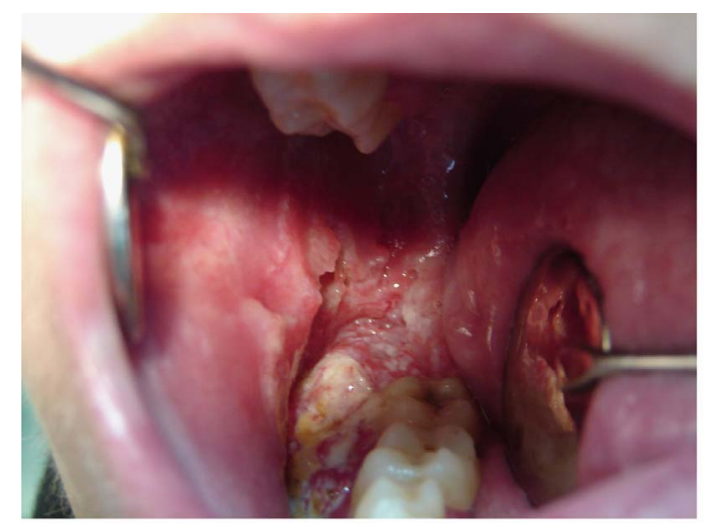

(a)



(b)

Figure 1. Intraoral view of the lesion.

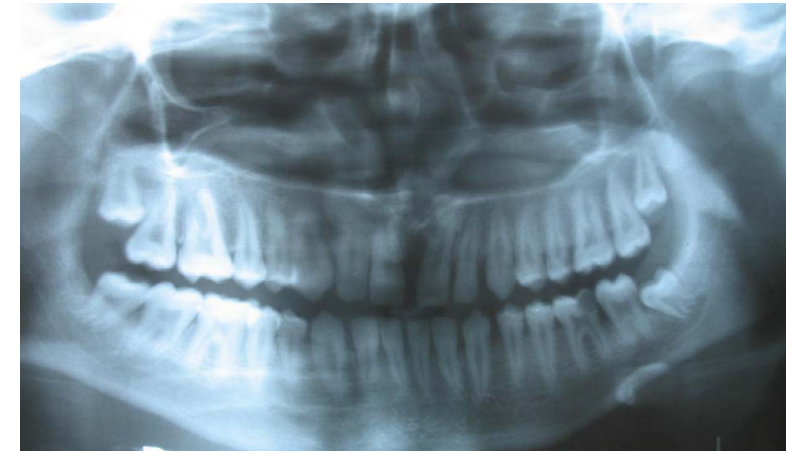

Figure 2. Radiographic view of the patient.

cules; size of big one was $0.8 \times 0.5 \times 0.2 \mathrm{~cm} .1 / \mathrm{Y}$. Histopathologic images of the lesion were shown in Figure 3(a) and (b).

Three times of the radiotherapy (totally $32 \mathrm{GY}$, external) was applied and radiation injury (burn) was occured as a complication. Radiotherapy treatment was stopped, he refused to be fed with nasogastric cathater. He died few months later because of malnutrition. An autopsy was not obtained.

\section{DISCUSSION}

We report a rare case of oral SCC originating in the mandible of a 16-year-old male patient with chronic graftversus-host disease 10 years after HLA-identical sibling bone marrow transplantation for FA. The case highlights the problems of malignant change in FA and also the increased risk of second malignancy after BMT.

FA is a highly heterogeneous syndrome, in which homozygotes may show congenital anomalies and hematological problems. The main cause of morbidity and mortality are aplastic anemia, myelodysplasia and Although acute myeloid leukemia is the most commonly found malignancy, solid tumors represent about $40 \%$ of neoplasms observed which develop at older ages in patients surviving the hematologic abnormalities [5].

Kuttler in 2003 referred that 19 of 754 patients in the International Fanconi Anemia Registry (3\%) had hard neck squamous cell carcinoma (HNSCC) [3]. The male: female ratio of $\mathrm{HNSCC}$ in normal population is 2:1 while Reed asserted the reversed ratio in FA patients [13]. FA patients develop SCC at significantly earlier age than the general population. Kenedy and Hart reported an average age of 27 years in FA patients [14] and the average time between age of FA diagnosis and cancer development is 10.5 years [15].

As observed in the case presented in this paper, SCC associated with FA develops earlier than in general population and shows a more aggressive behaviour. Furthermore, in contrast to FA-nonaffected individuals, predisposing risk factors for head and neck cancer, like 
Squamous cell carcinoma showing large areas of keratinisation (HE 100 $\times)$

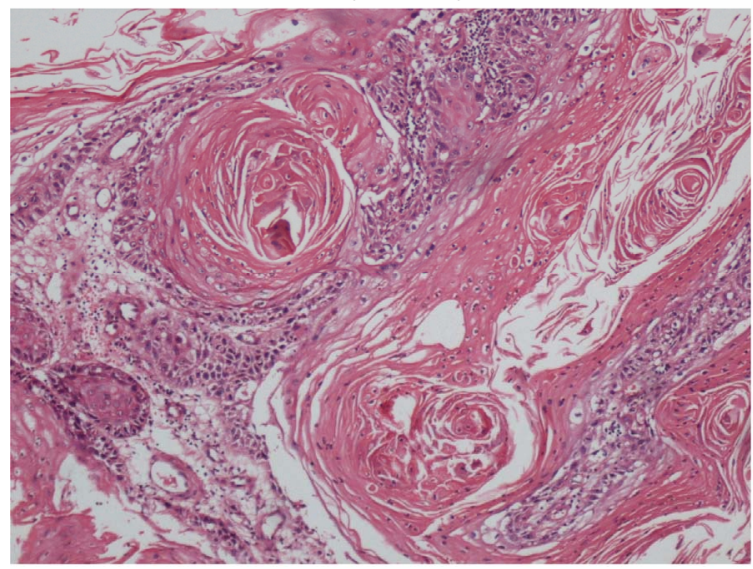

(a)

Squamous cell carcinoma. Individual cell keratinisations are seen (HE 200×)

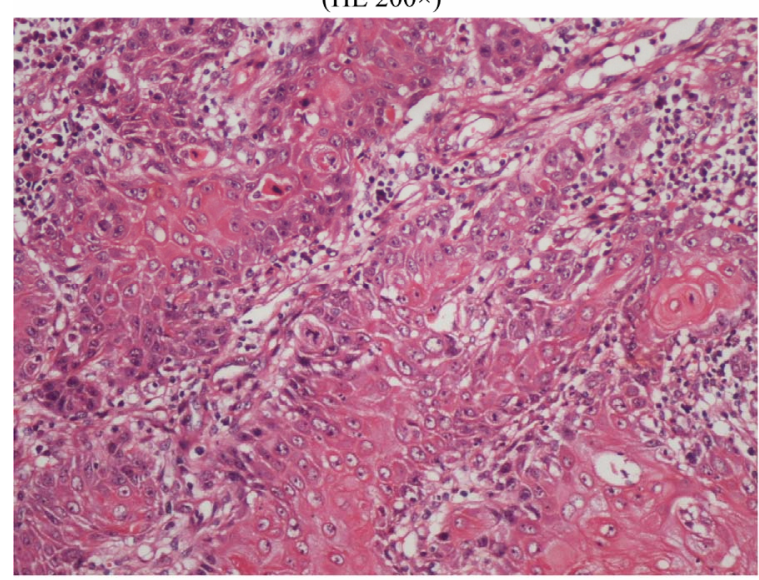

(b)

Figure 3. Histopathologic images of the lesion.

tobacco and alcohol abuse, are rare in these patients. Jansisyanont reported that the commonest localizations of SCC in FA patients in descending order are: tounge, anogenital region, pharynx, larynx, oral [5] mucosa, mandible and skin [16].

In this report, development of malignancy occured 10 years after BMT, which is a longer period than that observed by Deeg et al. who reported that malignancy development occured in a peak between 8 and 9 years after BMT [5].

Although FA appears to be genetically heterogeneous, all cases display abnormalities of DNA repair. A gene defective in one of the four subsets of FA patients has been defined. Defects in this gene are thought to play a role in the development of neoplasia in FA patients. However, many other factors may also contribute to the development of malignancies. Some of the authors suggested that patients that have endured BMT have a greater incidence of malignancies development. In these patients, there are four additional factors including pretransplant total body irradiation, cyclophosphamide treatment, chronic GvHD, and prolonged immunosuppresive treatment after transplantation [2,15-17].

Most patients who develop malignancy after BMT also have chronic GvHD. Additionally, some authors observed the development of such tumors on sites initially involved with GvHD-related inflammatory processes [5].

It was proposed that TBI and certain treatments for acute GvHD were risk factors in the development of secondary tumors. Lishner et al., also reported solid tumors in patients with chronic GvHD after BMT for a variety of conditions including aplastic anemia [18]. A single patient with FA who developed SCC of the tounge at age 29, 10 yeras after BMT complicated by chronic GvHD, has been reported [19]. A 12 year old boy with FA developed SCC of the tounge 74 months after BMT [20]. It was estimated by the same investigators that there is a 22-fold higher risk of solid tumor development in patients transplanted for aplastic anemia (AA) than in the general population. Salum et al; reported the case of a 12-year-old patient with FA who had been submitted to BMT at the age of 5 and exhibited oral lesions characteristic of chronic GvHD. Eleven years after the BMT, he developed SCC of the tongue with an aggressive behavior, which was considered an untreatable condition [5]. Millen et al, reported a case of oral SCC originating in the buccal mucosa of an 18-year-old fe- male patient with chronic GvHD 9 years after HLA-identical sibling BMT for FA. They supported that the patient could be seen to have had multiple risk factors including genetic predisposition, pretransplant conditioning with both cyclophosphamide and TBI, chronic GvHD and prolonged immunosuppresive treatment [18]. The patient presented in this case report showed GvHD following the bone marrow transplantation, four weeks later CMV sepsis was developed.

Abdelsayed et al. advocated that oral cancer in patients with GvHD may have an aggressive biologic potential with increased tendency for recurrence and development of new lesions [5].

Spardy et al. suggested that FA patients have an incresed risk for SCC at sites of predilection for infection with high-risk human papillomavirus types including the oral cavity and the anogenital tract. They established that the FA pathway as an early host cell response to high-risk HPV infection [21].

The patients with FA may be particularly susceptible to HPV-induced carcinogenesis [3]. HPV vaccines, which are currently under development, might help to prevent HPV infection in both the cervix and the oropharynx [22]. 
Mario AJA Hermsen et al., examined oral SCC tissue from two FA patients by comparative genomic hybridization. Both tumors, which were negative for human papilloma as well as Epstein-Barr viral sequences, showed multiple alterations with a high proportion of whole-arm chromosomal gains and losses. In contrast to the suggestions above; some other authors put forward that, the process leading to early occurence of oral cancer in FA patients follows a similar pathway as in nonFA cancer patients, which would support a caretaker function for FA genes in the protection against oral carcinogenesis [23].

The patient was tested for HPV by PCR and DNA sequencing. Tumor was detected with oncogenic 15 types of HPV (HPV-16, HPV-11, HPV- 16, HPV-18, HPV-31, HPV-33, HPV-35, HPV-39, HPV-45, HPV-51, HPV-52, HPV-56, HPV-58, HPV-59, HPV-68). In this case report, the human papillomavirus status was found negative according to comparative genomic hybridization (sample was taken from serum).

The treatment of malignancies in FA patients with Had and Neck SCC is similar to the general population with similar pathologies. The aim is the tumour resection oncologic radicality. The main preoperative problem in patients wih FA is the associated bone marrow failure, requiring preoperative haematologic consultations. The possibility of blood and platelet transfusion before surgery must be considered. The first approach in FA patients is surgical resection of primary HNSCC with neck dissection and reconstruction if necessary. Generally, FA patients withstand surgical procedures very well. A further concern for the surgeon is the development of postoperative complications, including wound infections and haematoma $[3,15,16]$. In this case report, following the tomographic examination, it was decided as a primer carcinoma with lemph metastasis that couldn't be resected.The patient that couldn't be applied chemotherapy underwent local radiotherapy with occular shielding. After third dosage of the radiotherapy, radiation injury (burn) was occured as a complication. Radiotherapy treatment was stopped, he refused to be fed with nasogastric cathater. He died few months later because of malnutrition.

\section{CONCLUSIONS}

This case highlights the susceptibility of FA patients to malignant tumour development. The applicability of BMT is increasing and surviving cohorts are expanding in number, so the incidence of secondary malignancy is likely to rise. Early intervention may be translated into improved survival, or at least may reduce the necessity for more aggresive surgical approaches. We agree with the potocol proposed by Kutler [3]. He suggests a care- ful biannual screening of the oral cavity and oropharynx that should start between the ages of 15 and 20. However, in patients with FA with history of leucoplakia or recurrent oral lesions, head and neck examinations are recommended every six or eight weeks.

\section{ACKNOWLEDGMENTS}

We thank to Dr Hüseyin Kemal Türköz for his support for the evaluation of the histopathologic images. (Department of Pathology, University of Marmara, School of Medicine).

\section{REFERENCES}

[1] Oksüzoğlu, B., Yalçin, S. Ann Hematol. (May 2002) 81, 294-298. Epub 2002 May 3. doi:10.1007/s00277-002-0455-6

[2] Somers, G.R., Tabrizi, S.N., Tiedemann, K., Chow, C.W., Garland, S.M., Venter, D.J. (July-August 1995) Pediatric Pathology \& Laboratory Medicine, 15, 597-607.

[3] Kutler, D.I., Auerbach, A.D., Satagopan, J., Giampietro, P.F., Batish, S.D., Huvos, A.G., Goberdhan, A., Shah, J.P. and Singh, B. (January 2003) High incidence of head and neck squamous cell carcinoma in patients with Fanconi anemia Archives of Otolaryngology-Head \& Neck Surgery, 129, 106-112. doi:10.1001/archotol.129.1.106

[4] Alter, B.P. 1996 Fanconi's anemia and malignancies. American Journal of Hematology, 53, 99-110. doi:10.1002/(SICI) 1096-8652(199610)53:2<99::AID-AJ $\mathrm{H} 7>3.0 . \mathrm{CO} ; 2-\mathrm{Z}$

[5] Salum, F.G., Martins, G.B,, de Figueiredo, M.A., Cherubini, K., Yurgel, L.S. and Torres-Pereira, C. (2006) Squamous cell carcinoma of the tongue after bone marrow transplantation in a patient with Fanconi anemia. Brazilian Dental Journal, 17, 161-165. doi:10.1590/S0103-64402006000200015

[6] Alter, B.P. (2003) Cancer in Fanconi anemia, 1927-2001. Cancer, 97, 425-440. doi:10.1002/cncr.11046

[7] Rosenberg, P.S,, Grene, M.H. and Alter, B.P. (2003) Cancer incidence in persons with Fanconi anemia. Blood, 101, 822-826. doi:10.1182/blood-2002-05-1498

[8] Auerbach, A.D., Rogatko, A. and Schroeder-Kurth, T.M. (1989) International fanconi anemia registry: Relation of clinical symptoms to diepoxybutane sensitivity. Blood, 73, 391-396.

[9] Joenje, H., Levitus, M., Waisfisz, Q., et al. (2000) Complementation analysis in Fanconi anemia: Assignment of the reference FA-H patient to group A. American Journal of Human Genetics, 67, 759-762. doi:10.1086/303067

[10] Timmers, C., Taniguchi, T., Hejna, J., et al. (2001) Positional cloning of a novel Fanconi anemia gene, FANCD2. Molecular Cell, 7, 241-248. doi:10.1016/S1097-2765(01)00172-1

[11] Linares, M., Pastor, E., Gomez, A. and Grau, E. (1991) Hepatocelluler carcinoma and squamous cell carcinoma in a patient with Fanconi's anemia. Annals of Hematology, 63, 54-55. doi:10.1007/BF01714963

[12] Moldvay, J., Schaff, Z., Lapis, K. (1991) Hepatocellular carcinoma in Fanconi's anemia treated with androgen 
and corticosteroid. Zentralblatt fur Pathologie, 137, 167-170.

[13] Reed, K., Ravikumar, T.S., Gifford, R.R., Grage, T.B. (1983) The association of Fanconi's anemia and Squamous cell carcinoma. Cancer, 52, 926-928. doi:10.1002/1097-0142(19830901)52:5<926::AID-CNC R2820520530>3.0.CO;2-T

[14] Kennedy, A.W., Hart, W.R. (1982) Multiple squamous cell carcinomas in Fanconi'anemia. Cancer, 50, 811-814. doi:10.1002/1097-0142(19820815)50:4<811::AID-CNC R2820500432>3.0.CO;2-I

[15] Lustig, J.P., Lugassy, G., Neder, A. and Sigler, E. (1995) Head and neck carcinoma in fanconi's anemia-report of a case and review of the literature. European Journal of Cancer Part B: Oral Oncology, 31, 68-72. doi:10.1016/0964-1955(94)00044-5

[16] Jansisyanont, P., Pazoki, A. and Ord, R.A. (2000) Squamous cell carcinoma of the tongue after bone marrow transplantation in a patiant with Fanconi's anemia. Journal of Oral and Maxillofacial Surgery, 58, 1454-1457. doi:10.1053/joms.2000.19212

[17] Socie, G., Scieux, C., Gluckman, E., Soussi, T., Clavel, C., Saulnier. P., Birembault, P., Bosq, J., Morinet, F. and Janin, A. (1998) Squamous cell carcinoma after allogenic bone marrow transplantation for aplastic anemia: Further evidence of a multistep process. Transplantation, 66, 667-670. doi:10.1097/00007890-199809150-00023

[18] Millen, F.J., Rainey, M.G., Hows, J.M., Burton, P.A, Irvine, G.H. and Swirsky. D. (1997) Oral squamous cell carcinoma after allogenic bone marrow transplantation for Fanconi anemia. British Journal of Haematology, 99, 410-414. doi:10.1046/j.1365-2141.1997.3683184.x

[19] Bradford, C.R., Hoffman, H.T., Wolf, G.T., Carey, T.E., Baker, S.R. and McClatchey, K.D. (1990) Squamous cell carcinoma of the head and neck in organ transplant recipients: Possible role of oncogenic viruses, The Laryngoscope, 100, 190-194.

[20] Socie, G., Henry-Amar, M., Cosset, J.M., Devergie, A., Girinsky, T. and Gluckman, E. (1991), Increased incedence of solid malignant tumors after bone marrow transplantation for sever aplastic anemia. 78, 277-279.

[21] Spardy, N., Duensing, A., Charles, D., Haines, N., Nakahara, T., Lambert, P.F., Duensing, S. (December 2007) The human papillomavirus type 16 E7 oncoprotein activates the Fanconi anemia (FA) pathway and causes accelerated chromosomal instability in FA cells. The Journal of Virology, 81, 13265-13270. doi:10.1128/JVI.01121-07

[22] Gillison, M.L. and Lowy, D.R. (2004) A casual role for human papillomavirus in head and neck cancer. The Lancet, 363, 1488-1489. doi:10.1016/S0140-6736(04)16194-1

[23] Hermsen, M.A., Xie, Y., Rooimans, M.A., Meijer, G.A., Baak, J.P., Plukker, J.T., Arwert, F. and Joenje, H. (2001) Cytogenetic characteristics of oral squamous cell carcinomas in Fanconi anemia. Familial Cancer, 1, 39-43. doi:10.1023/A:1011528310346 